\title{
A Research to Construct the Interactive Platform for Integrated Information of Agricultural Products in China Xinjiang
}

\author{
Yuan $\mathrm{Li}^{1, *}$ and Zhigang $\mathrm{Li}^{2, * *, * * *}$ \\ ${ }^{1}$ School of Economic \& Trade, Shihezi University, Shihezi, Xinjiang, 832003, China \\ ${ }^{2}$ College of Information Science \& Technology, Shihezi University, \\ Shihezi, Xinjiang 832003, China \\ lzg_infeshzu.edu.cn
}

\begin{abstract}
Xinjiang is located on the northwest border of China, which is an important agricultural production and export base. In order to establish integrated management of agricultural products and service information system, China put forward the "Golden Agriculture Project" program in 1994, whose construction development is still insufficient because of the backward informatization level in Xinjiang. This article uses the management theory to analyze the shortcomings of the current three information platforms for agricultural products, based on the current situation of the Xinjiang's informationization and the different demand for information of each node on the supply chain of agricultural products. Proposing an interactive platform for integrated information of agricultural products which combines farm production, supply and marketing of Xinjiang agricultural products. This will help the information platform to play the role of information collection and distribution, and to improve the efficiency of the circulation of Xinjiang agricultural products.
\end{abstract}

Keywords: Xinjiang, Agricultural Products, Interactive Platform for Integrated Information.

\section{Introduction}

Agriculture is the foundation of the national economy, and the vicissitudes of agriculture related to the whole national economy. With the advent of information age, the agricultural industry is using modern technology to produce scientifically instead of the traditional production mode. Meanwhile, many scholars have been paying attention to issues on the flow of the agricultural products. Frank and Henderson thought that recent researches on the flow of agricultural products had focused on the vertical coordination, ignored the vertical integration (Frank and Henderson, 1992). Zhang, a domestic scholar, whose research combined with the theory of agriculture economics, believed that the flow of agricultural products was a link of production, purchase,

* The main research areas are logistics and supply chain management.

** Associate Professor, The main research areas are Supply Chain Management and Information Management and System.

**** Corresponding author.

D. Li, Y. Liu, and Y. Chen (Eds.): CCTA 2010, Part III, IFIP AICT 346, pp. 500-511, 2011.

(C) IFIP International Federation for Information Processing 2011 
transportation, storage, and the information activities of agricultural products, etc (Qian Zhang, 2003).

With the unceasing enhancement of agricultural production efficiency, the agricultural product circuit problem is highlighted gradually. A healthy development of agriculture needs a nice basement that every entity on agriculture industry chain has good cooperation (Yuheng Zhao, 2006), and information sharing is the key point to ensure the coordination in the agricultural industry chain (Song Zhou et al., 2007). Therefore, various countries built many kinds of agricultural product information platforms. As the strongest electronic information industry country in the world, United States has completed the world biggest agriculture computer network system AGNET (Xingong Li, 2003). Because of regional reason, Japan paid more attention to informationization construction of agricultural product circulation, which promoted the separation between physical distribution and the commercial interchange, and accelerated the smooth flow of goods (Chunyi Cao, 2008).

China joined the Internet in May 1994, as the 71st national-level network. In December, China proposed the plan named "Golden Agriculture Project" in the third conference of "national economy informationization joint conference", which aimed to accelerate agricultural and rural agricultural information, and established the integrated management information system and services (Hengyou Yang, 2007). In 2005, "thousands of villages" market engineering was sponsored by the Department of Commerce, which was combined with developing of rural information, building the new system of the agricultural products circulation, and solving the problems such as the circulation of primary agricultural products. Now our agricultural information platforms are still lagging behind, especially in the mid and western agricultural provinces. The information technology worked inefficiently to play the role of agricultural products circulation (Chunyi Cao, 2008).

Xinjiang is situated at the northwest border region of China, the land area accounts $1 / 6$ of the national total area. At the end of 2008, the total cultivated area was 4124.56 thousand hectares in Xinjiang, which accounted 3.39\% for the nation total cultivated area -121715.9 thousand hectares. The number was situated national 14th. The average cultivated area per person is 2.9 Chinese acres, situated national $4 \mathrm{th}^{1}$. In China, Xinjiang agriculture has advantages of large-scale and intensive compared with other areas. At present, Xinjiang agriculture has a "three pillars" pattern, featuring the farming, the animal husbandry and fruit horticulture. Therefore, Xinjiang is building an agricultural integrated information platform; will play an important role to accelerate agricultural development and products circulation.

\section{The Significances and Functions of Constructing an Interactive Platform of Integrated Information for Agricultural Products}

Interactive platform of integrated information is a website that set the information of agricultural production, supply, and marketing for the whole. It can play important role in speeding up the circulation of agricultural products, promoting the process of agriculture informationization, and accelerating development of agricultural.

\footnotetext{
${ }^{1}$ The data originate from "China Statistical annual" (2009), the partial data obtain through the data computation.
} 
The characteristics of a small population and vast land in Xinjiang enable its agricultural development to have certain formalization superiority. In 2008, the cotton output in Xinjiang was 302.6 million tons and beetroots was 438.9 million tons, ranked 1st in China; the output of fruits, oil-bearing crops, food foodstuff were 855.0, 56.8 and 930.5 million tons respectively, were separately situated the 7 th, 13 th, $21 \mathrm{st}$ in China $^{2}$. In recent years, rapid development of agriculture expanded agricultural export. Table 1 shows the total exports were 7.9 billion dollars in Xinjiang by 2009, which declined $43.9 \%$ but was almost the same as 2008 . Therefore, the exports of agricultural products have become a major part of Xinjiang foreign trade boost.

Table 1. Xinjiang agricultural exports

Unit: billion dollars

\begin{tabular}{llllll}
\hline Year & $\begin{array}{l}\text { Xinjiang's } \\
\text { agricultural } \\
\text { exports }\end{array}$ & $\begin{array}{l}\text { Xinjiang's } \\
\text { total } \\
\text { exports }\end{array}$ & $\begin{array}{l}\text { Percentage } \\
\text { of total } \\
\text { Xinjiang's } \\
\text { exports (\%) }\end{array}$ & $\begin{array}{l}\text { National } \\
\text { agricultural } \\
\text { exports }\end{array}$ & $\begin{array}{l}\text { Percentage } \\
\text { of total } \\
\text { national } \\
\text { exports (\%) }\end{array}$ \\
\hline 2006 & 4 & 71.39 & 5.6 & 160.7 & 2.49 \\
2007 & 5.97 & 115.03 & 5.19 & 370.1 & 1.61 \\
2008 & 8.12 & 193.99 & 4.19 & 404.9 & 2.01 \\
2009 & 7.9 & 108.2 & 7.3 & 395.9 & 2 \\
\hline
\end{tabular}

Data sources: From Xinjiang Statistical Yearbook 2009, China Agriculture Yearbook, The People's Republic of China Central People's Government Network, China Agricultural Information Network and Hunan Agricultural Science and Technology.

However, exports of agricultural products in Xinjiang are mostly fruits and other primary agricultural products, and they are affected by the seasonal factor seriously. In addition, Xinjiang locates at a special geographical position and the relatively backward transport is a disadvantage in its distribution and export of agricultural products. Therefore, building an integrated information interactive platform for agricultural products in Xinjiang has an important role in the circulation of agricultural products.

Firstly, building agricultural information interactive platform can provide a intercommunion platform for the agricultural product, supply and sales, speed up the flow of the agricultural product information, promote agriculture informationization development in Xinjiang, and accelerate circulation of the agricultural products (Yuheng Zhao, 2006), atone the insufficiency from the geographical position and backward transportation condition, as well as avoid backlog of agricultural products.

Secondly, the establishment of interactive platform of integrated information will strengthen the relationship between farmers and agribusinesses, agribusiness enterprises and agribusiness enterprises, enterprises and their clients, as well as between government and the enterprises combined with farmers. In addition, the transaction cost $t$ caused by asymmetry of information can also be reduced to this construction. Furthermore, from that we can strengthen the communication between the two agribusinesses horizontally, deepen the communication among the agribusiness, customers and governments vertically, and eventually construct a perfect products circulation system on the whole.

\footnotetext{
${ }^{2}$ The data originates from "China Statistical Yearbook" (2009).
} 


\section{The Problems on the Current Interactive Platform for the Agricultural Products Information in Xinjiang}

\subsection{A Brief Introduction to the Current Interactive Platform for Agricultural Products Information in Xinjiang}

At present, the agricultural website is an effective, quick and common platform for agricultural information interaction. Xinjiang has three well-know agriculture websites: Xinjiang Xingnong Website (http://www.xjxnw.gov.cn), Xinjiang agricultural information network (http://www.xj-agri.gov.cn) and Eight Acres of Xinjiang (http://www.bamudi.com/xinjiang/Default.html).

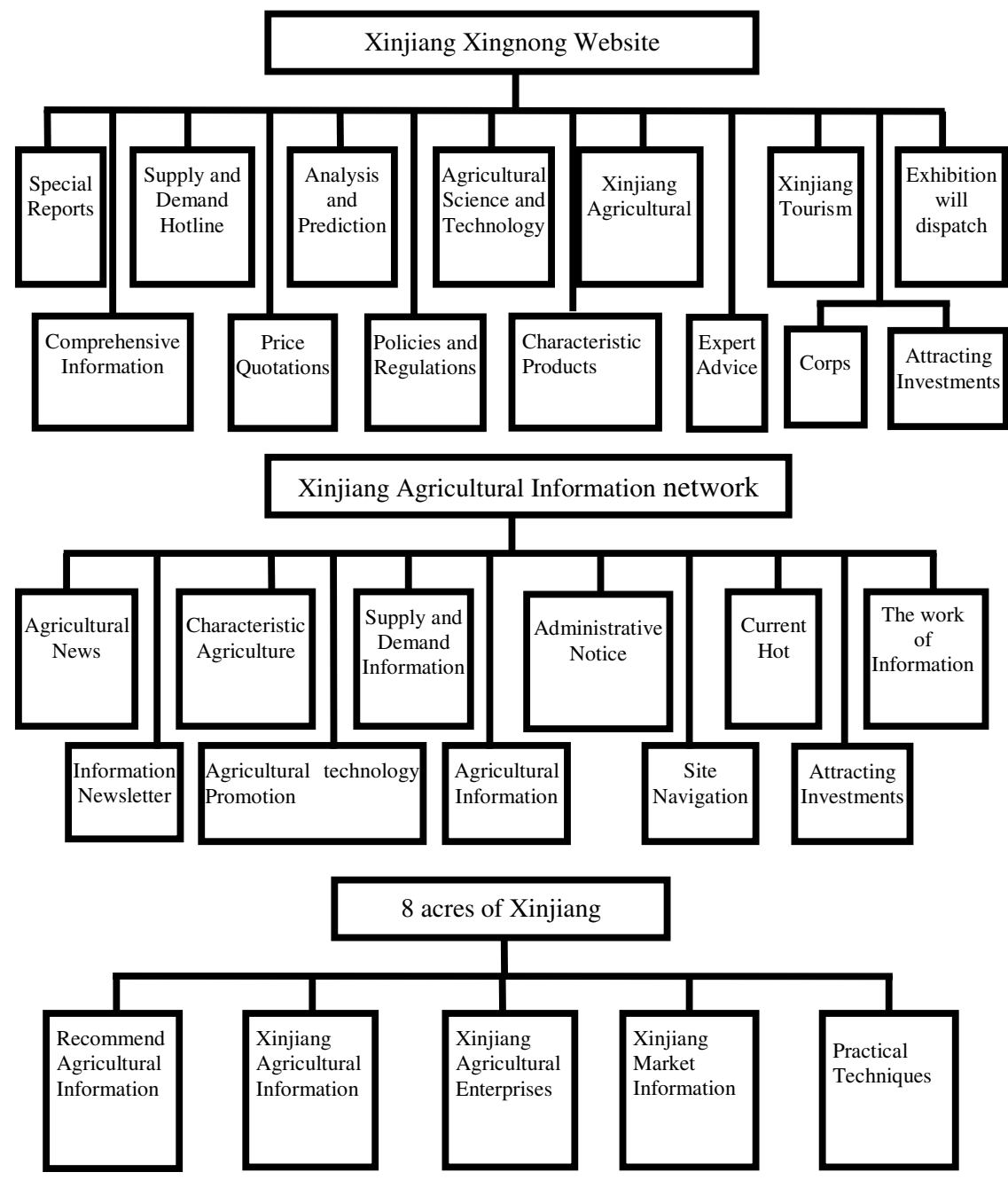

Fig. 1. The main Structure of Agriculture Website in Xinjiang 
Xinjiang Xingnong Website is sponsored by Xinjiang Uygur Autonomous Region Meteorological Bureau, and Urumqi Municipal Meteorological Bureau undertakes its construction. It is an agricultural service website including information collection, editing, processing, and distributing. It is also the central website of the integrated information network system of Xinjiang agriculture. Figure 1 shows an example; Xinjiang Xingnong Website collected many aspects of information including agriculture, forestry, animal husbandry, meteorology, tourism, ecology, economy and environment etc.

Xinjiang agricultural information network is sponsored by Department of Xinjiang Uygur Autonomous Region, which is undertaken by the department of agriculture information center. Figure 1 show that Xinjiang agricultural information network focuses on agriculture policies issues, which helps farmers and agribusinesses understand new policies, also introduces the dynamic characteristics of Xinjiang agricultural products.

8 acres of Xinjiang is a self-service information interactive platform. It is a rural Internet information service platform, mainly collects information about agricultural consultation, enterprise exhibition, products promotion and user interaction. This platform joined the enterprises database, make up for the insufficiency of Xinjiang agricultural information interaction platform, and solved information sharing between production and supply.

\subsection{The Shortcomings of the Current Interactive Platform for the Agricultural Products Information in Xinjiang}

Although Xinjiang has established some agricultural information interaction platforms, these platforms still have many problems about construction and design.

\subsubsection{The Constructor of the Platform is Single}

As revealed in Figure 1, the subject of Xinjiang agricultural information interaction platform is mainly governmental, but industry, enterprise and others are not actively involved, which will affect the platform's effectiveness, reliability and comprehensiveness. The main reason is government obtained information is secondhand information, and their energy and time are limited, so information it collected is also limited.

\subsubsection{The Design of the Platform Has Problems}

Xinjiang Xingnong Website has already formed three levels of agricultural comprehensive economic information network but not established its own enterprise databases and professional logistics database from the platform design. There is very limited supply and demand information published on website. While the main agricultural products in Xinjiang is fruit, which are affected by seasonal factor seriously. Therefore, this website is actually not agriculture enterprise information exchange center.

Without enterprises information, Xinjiang agricultural information network cannot attract the agricultural enterprise's attention. On the platform, farmers cannot find 
useful information about agriculture enterprises, and cannot achieve information sharing goal of the production, supply, and sale.

8 acres of Xinjiang network does not resolve the problems either, those in the same platform, agribusinesses can obtain and share information from the purchase to sell agricultural products.

Looking from the platform designs, Figure 2, the Xinjiang agricultural products circulation pattern shows the agricultural information platforms provide the supply and demand information. It plays certain but not significantly role to seek partner for agricultural products. Firstly, the information interaction platform lacks of subsystem about agriculture enterprise information, and it is disadvantage of enterprise to receive the production information. Secondly, three platforms only supplied source of goods information for the agricultural enterprise and the sales enterprise, but did not combine agricultural material sale with logistics service ${ }^{3}$, and did not established information sharing mechanism about distribution, processing, procurement, and diversification etc.

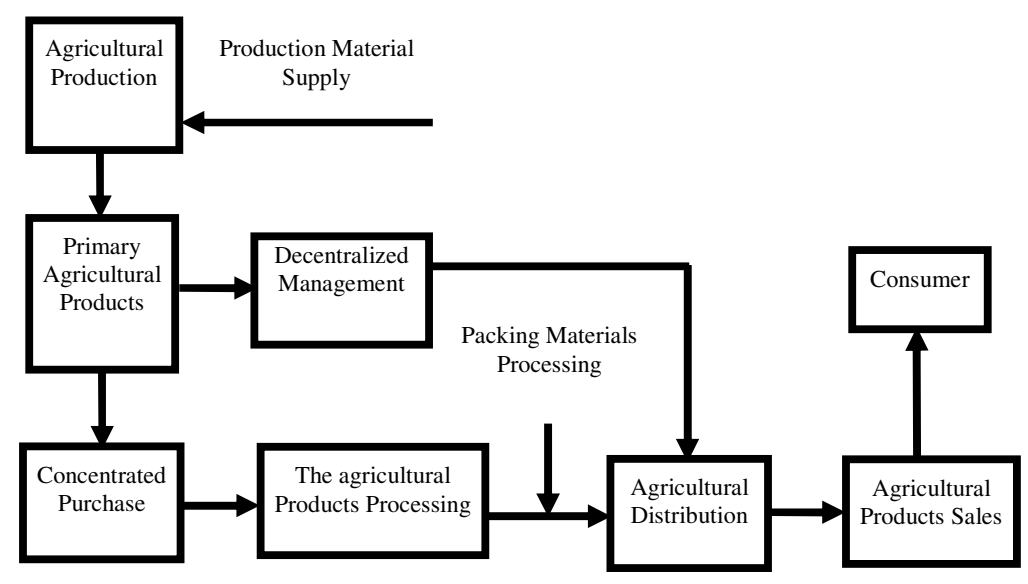

Fig. 2. Xinjiang Agricultural Circulation Pattern

\subsubsection{Insufficient Use of the Platform}

The purpose of constructing agricultural information is to transmit the related information. However, the current situation in Xinjiang shows these platforms were not fully used. Visiting information platform needs some equipments and skills, but famers, who are the main body of the agricultural products, are not involved well. It is due to the capital and own quality reason (Lining Gong, 2009). All of these leads to a contradiction that famers who are one of the main service objects cannot enjoy the convenience and benefits brought by the platforms.

\footnotetext{
${ }^{3}$ The department of commercial affairs had promulgated in March 10, 2008 《about Speeds up Our country Current distribution realm Modern Physical distribution Development Instruction Opinion》 (business changes sends [the (2008)53 number)] to propose.
} 


\section{The Construction of the Interactive Platform of Integrated Information for Xinjiang's Agricultural Products}

\subsection{The General Idea}

The Interactive Platform of Integrated Information for Xinjiang's Agricultural Products is a collection of agricultural products information from production to sale. It can satisfy every node's demand of information in the supply chain of agricultural products, consequently optimize the whole process of the supply chain. Therefore, the construction of the platform should take the market demand as guidance, obey the principle of overall planning, develop step by step, and continuous improve and make the enterprise as the main form (Baiqing Diao, 2003). The formation of the interactive situation should take the platform constructed by the regions of developed informationization as guidance, and support participation of the regions of less developed informationization (Xuedao Wan, 2008). The construction of the platform should also focus on publicizing and brand.

\subsection{Function of the Platform}

To achieve the goals of spreading the information of every node in the production, supply and sale of the agricultural products, the function of the platform should be:

(1) Function of publishing graphic and text information. Much information is published in the form of picture and text, including policies and regulations, production technology and work trends, etc. Farmers are the main users, so their understanding ability of the information should be considered. Thus, the information of the platform should be easily understood for all kinds of people.

(2) Function of data exchange. The information demander should easily get electronic data from the platform. The platform should also have the function of data input and output, upload and download, as well as file printing spreading varied file format, such as the XML, TXT and EXCEL.

(3) The retrieval functions. Some necessary databases should be established to make users get their information through searching by keywords.

(4) VOD function. Users could get some video resources about the demonstration of the agricultural production technology, agricultural training courses, expert lectures and so on.

(5) Communicating function. Platform should provide communication function to farmers, enterprises, customers and related government departments (Kliebenstein and Lawrence, 1995).

\subsection{Software and Hardware Requirements}

The construction of the platform needs some hardware, mainly including network equipments, host and storage devices, network security equipment, etc (Tao Yin, 2006). In terms of software, to establish the database of agriculture information with search function, the construction of the digital information resources should be strengthened. In terms of the content of the database, it should include the database of the agricultural resources information, the agricultural factors of production 
information, the agricultural technology information, the market information of agricultural products, the agriculture policies and rules information and the agriculture agency information, etc. In terms of the type, the resources of the database should include picture data, text data, interspaces data and the analyzed data, etc. Therefore, the construction of the database of the platform should obey the principle of centralization, unification, criterion and efficiency, i.e. central construction, unified compatibleness, resource sharing, efficient appliance to form a centralized and regulated system of database (Ming Lu, 2009). The construction of the information resources of the platform should be unified planning. The collection and classification of the information and the exploitation of the database and item should use uniform criteria.

\subsection{The Design of the Platform Content}

The platform constructed in this article added the subsystem of the corporation information and information exchange to the original platform. It started with the whole life cycle of the agricultural products, and constructed data sharing platform for the production, supply and sale of the Xinjiang agricultural products and the regulators to decrease the cost of every section in the supply chain to get information.

The platform consists of three levels: the service layer, the information sharing layer and the basic function layer (Figure 3 shows the details) (Xiaohui Liu, 2007). The service layer provides various services to the users of the platform. The information sharing layer is the external manifestation, namely the web interface of the platform. The basic function layer are the various function which supported by the background database.

The background database includes the foundation of the agriculture information resources database, the policies and rules information database, the agricultural science and technology information database, the rural public information database, the agriculture work trends information database, the information exchange system database, the products information database and the enterprise information database. The functions of each database are as follows:

(1) The foundation of the agriculture information resources database introduces the administrative planning, the status of the economic and social development and the natural resources of Xinjiang, such as the climate, the animal husbandry, the output of the main crops and the proportion of the land and the cultivated land.

(2) The subsystem of the policies and rules consists of the agriculture-related legal and regulatory information, the rural security information, the emergency procedures of public events information and the government public information issued by the supervise department. It can help farmers know the current agriculture-related policies and assist farmer and manufacturing enterprises to make decisions with the market trends.

(3) The agricultural science and technology information database provides the practical science and technology for the production of the agriculture and animal husbandry according to different climates and production environments. It offers assorted technical support to the production, pest control, daily management in the planting, animal husbandry, fruit and vegetable gardening industry. Meanwhile, it introduces new products and technology to agricultural production enterprises and assists the production department of producing agricultural goods to plant scientifically. 


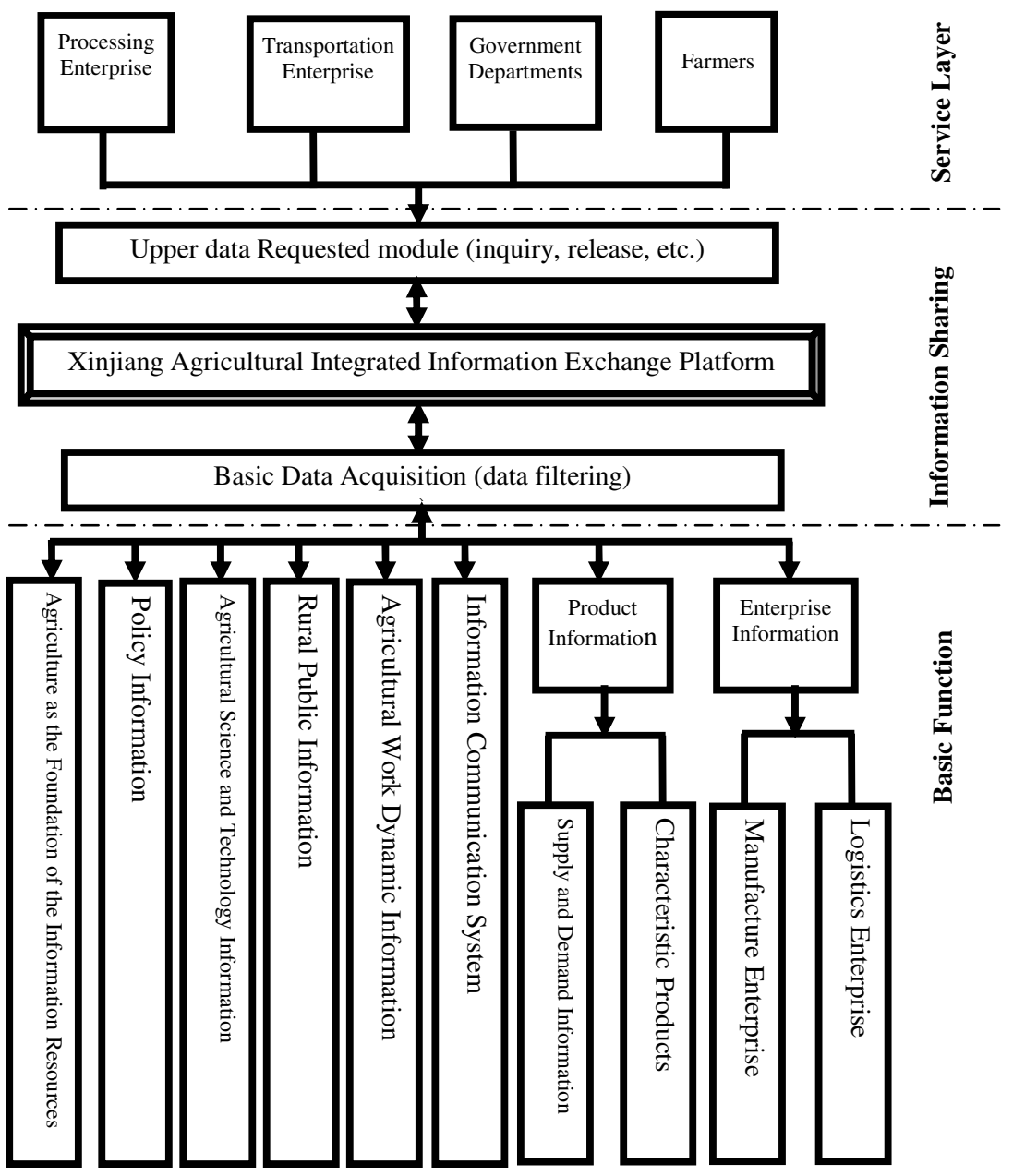

Fig. 3. The Xinjiang Agricultural Interactive Platform

(4) The rural public information database focuses on the construction of the rural social culture, the grass-roots party and the service on the medical and health service. It provides the public service on the rural information around the construction of the new rural construction and the harmonious society.

(5) The agriculture work trends information database reports the work trends of the agriculture sector at all levels, introduces the agricultural work experience of different regions, publicizes the achievement of the new rural construction and shows the success of the agricultural work.

(6) The information exchange system database provides a platform for information exchange for farmers, agricultural production and processing enterprises, logistics companies and government departments to carry out the information exchange and sharing. Farmers could gain the technical guidance by consulting experts online. 
(7) The products information database issues the demand and supply information and introduces characteristic agricultural products. It provides a platform for farmers to issue the demand and supply information. It supplies the wholesale price, demand and supply information of all regions in Xinjiang, reduces the cost of getting information each other and to speed up the circulation of agricultural products. The information of characteristic agricultural products is about the advantageous agricultural products in the region. It publicizes and recommends the characteristic agricultural products by pictures and texts though the platform.

(8) The enterprise information database consists of the agriculture-related manufacturing and the logistics enterprises. It expands the awareness of the agriculturerelated enterprises through showing on the platform. It avoids the trouble in searching related information on different platforms by providing the information of the transportation and storage to the agriculture-related enterprises and the separated farmers. So they can deal with the problem of the supply, sale, transportation and storage of the agricultural products in the same platform.

\section{Several Issues Should be Paid Special Attention on the Construction of the Platform}

\subsection{The Relevant Laws, Regulations, Policies and Standards Should be Improved}

The construction of the platform should conform to the Informationization Regulations of Xinjiang. Rules and regulations on the information collection and updating, the information exchange and sharing, the management of the network and website and the management of the project should be improved continuously. The informationization criteria should be instituted and carried out. Especially the application of the criteria should be strengthened during the construction of the platform.

\subsection{The Government's Consciousness of Services Should be Strengthened}

The tenet of the platform construction is to provide public information service to the agriculture production and the agricultural products circulation. So governmental departments at all levels should attach importance to the construction of the platform. The construction of the platform should base on the principle of resources integration, relative concentration, servicing farmers, and facilitating enterprises, take the informationization as means (Songhai Yuan, 2009), and set the goals to speed up the circulation of the agricultural products (Cheng Wang, 2006). The vertical and horizontal contact should be strengthened to share the information through linking and exchanging the information.

\subsection{The Participation of the People of All Circles Should be Encouraged}

The construction of the platform could help the demander and supplier to gain related information, and it could also speed up the informationization development in Xinjiang, so the participation of the people at all sectors of the society should be encouraged. For example, the government would encourage the large-scale agribusiness and the agricultural cooperative organizations to develop and construct the platform, and those 
who produced a marked effect can receive tax incentives and other related incentives (Songhai Yuan, 2009).

\subsection{The Information Quality and Security Should be Noted}

The ability of the users to discriminate the information is limited, so the information quality and safety should be noted. Information quality includes the reliability of the information, namely the information is true and credible, and easily understanding, which means that farmers diathesis is lower and their understanding abilities of the information is limited, and the information should be easily to understand. Information security means malicious modification should be prevented; information security monitoring system should be established and improved continuously (Paulson, 2002).

\section{Conclusions}

In summary, the existing information platforms of Xinjiang agricultural products have shortcomings, so, this article attempts to build an interactive platform for integrated information of agricultural products in Xinjiang to satisfy the demand for information of each node on the chain of the farm production, supply and marketing the Xinjiang agricultural products, to achieve the purpose of information sharing, thereby to reduce the transaction costs, to promote the circulation of agricultural products, to decrease the risk, and to increase the income of farmers and enterprises. It can also help the government to regulate the agricultural products market effectively, and to maintain the order of the agricultural products market.

\section{References}

1. Cao, C.: Research and Implementation on Agricultural Products information platform based on Semantic Grid. Beijing University of Post and Telecommunications, Beijing (2008)

2. Chen, H.: Study on Agricultural logistics information portal. J. Rural Economy and Science-Technology 19(9), 43-44 (2008)

3. Diao, B., Li, X.: Planning and Design of Logistic \& Supply Chain System. Tsinghua University Press, Beijing (2003) (in Chinese)

4. Gong, B.: The Status and Trends on Agriculture Information Network Construction. J. Agriculture Network Information 8, 51-52 (2009)

5. Liu, X.: Logistics Information Management. China Logistics Publishing House, Beijing (2007) (in Chinese)

6. Lu, M.: Research on Agricultural information website design and function. J. Rural Science-Technology and Information 16, 16-17 (2009)

7. Wan, X.: A Study of the Construction of Rural Information Service Platform Based on Web in China. Beijing Forestry University, Beijing (2008)

8. Wang, C., Luo, B.: E-commerce Platform of IT Application to Agriculture of our Country Build Mode Analysis and Discussion. J. Science Technology and Industrial 6(1), 56-59 (2006)

9. Yang, H.: AHP-based agricultural information website evaluation. China Agricultural University, Beijing (2007) 
10. Li, X.: Constructing the system about agricultural informatization of government leading thought the experiences from the developed countries. J. Rural Economy 5, $42-43$ (2003)

11. Yang, X., Yang, Y.: Study on the Construction of Agriculture Information System. J. Journal of Hebei Agricultural Sciences 13(8), 145-147 (2009)

12. Yin, T.: Logistics Information Management. Dongbei University of Finance \& Economics Press, Dalian (2005) (in Chinese)

13. Yuan, S.: Development of agriculture website construction \& Play the agriculture information service functions. J. Shanghai Agricultural Science and Technology 4, 14-15 (2009)

14. Zhang, Q.: Discussion on Agricultural Products Logistics. J. Rural Economy 9, 48-50 (2003)

15. Zhao, Y.: A research to the Development of Agricultural Product Logistics System in Heilongjiang reclamation. Heilongjiang Bayi Agricultural University, Heilongjiang (2006)

16. Chen, Y.: Analysis of the way of spanning the last one-kilometer of agricultural information. J. Chinese Agricultural Science Bulletin 9(22), 462-465 (2006)

17. Frank, S.D., Henderson, D.R.: Transaction Cost as Determinant of vertical Coordination in the U. S. food industries. American Journal of Agricultural Economics 10 (1992)

18. Kliebenstein, J.B., Lawrence, J.D.: Contracting and vertical coordination in the United States pork industries. J. American Journal of Agricultural Economics 75, 1213-1218 (1995)

19. Loclde, S., Kitto, S.: Beyond the Farm Gate: Production-Consumption Networks and AgrjFood Research. J. Sociologia Ruralis 1 (2000)

20. Paulson, L.D.: Wanted: more network-security graduates and research. J. Computer 2, 22$24(2002)$

21. Zhou, S., Liu, G.-x., Chen, T.: Regional Country Information Service Platform Based on Hybrid Network. Science Technology and Engineering 4, 3435-3438 (2007)

22. The Central People's Government of the People's Republic of China, http://www.gov.cn/jrzg/2010-01/18/content_1513678.htm

23. http://www.gov.cn/jrzg/2010-01/18/content_1513678.htm

24. Ministry of Agriculture of the People's Republic of China, http: //www.agri.gov.cn

25. http://www. chinahyyj.com

26. Global Food Network, http: //www. foodqs.cn/news/gnspzs01/2008259398423.htm 